DEMOGRAPHIC RESEARCH

VOLUME 39, ARTICLE 33, PAGES 897-910 PUBLISHED 23 OCTOBER 2018

https://www.demographic-research.org/Volumes/Vol39/33/

DOI: 10.4054/DemRes.2018.39.33

Descriptive Finding

Persistence of death in the United States:

The remarkably different mortality patterns between America's Heartland and Dixieland

Wesley James

Jeralynn Cossman

Julia Kay Wolf

(C) 2018 Wesley James, Jeralynn Cossman \& Julia Kay Wolf.

This open-access work is published under the terms of the Creative Commons Attribution 3.0 Germany (CC BY 3.0 DE), which permits use, reproduction, and distribution in any medium, provided the original author(s) and source are given credit.

See https://creativecommons.org/licenses/by/3.0/de/legalcode. 


\section{Contents}

1 Introduction and background $\quad 898$

2 Data and methods $\quad 899$

3 Results 900

3.1 Preliminary findings 900

3.2 Time series findings $\quad 902$

4 Discussion 905

$\begin{array}{ll}\text { References } & 907\end{array}$ 


\title{
Persistence of death in the United States: The remarkably different mortality patterns between America's Heartland and Dixieland
}

\author{
Wesley James ${ }^{1}$ \\ Jeralynn Cossman ${ }^{2}$ \\ Julia Kay Wolf ${ }^{2}$
}

\begin{abstract}
BACKGROUND

Geographic disparities in mortality have been analyzed by place in myriad ways. Although the people who live in a place continuously change, the health characteristics of those places tend to stay the same; they are persistent. Our work analyzes persistence of mortality across various geographic designations and uncovers the wide-ranging disparities in death across the United States.
\end{abstract}

\section{METHODS}

Using 48 years of county-level mortality data, we analyze trends over time and disparities across places using rural-urban distinctions and census-based region and division classifications. Trends in death rates, excess deaths, and rates of mortality improvement are provided.

\section{RESULTS}

Findings support the hypothesis that persistently high mortality places are disproportionately concentrated in the rural South, particularly the East South Central division of Kentucky, Tennessee, Mississippi, and Alabama. The disparity between this division and urban America is wide and getting wider, and the disparity between this area of the South and the Midwest is alarming.

\section{CONTRIBUTION}

Our research moves forward the literature on place-based mortality disparities in two important areas by testing the notion of persistence of poor health in place, and by identifying geographic disparities based on classifications not previously tested.

\footnotetext{
${ }^{1}$ University of Memphis, Memphis, USA. Email: wljames1@memphis.edu.

${ }^{2}$ West Virginia University, Morgantown, USA.
} 


\section{Introduction and background}

Recent public health research documents geographic disparities in mortality in the United States. This literature takes many different forms, particularly regarding the way 'place' is conceptualized, operationalized, and measured. Death rates (and life expectancy) differ markedly between urban and rural counties (Cosby et al. 2008; Cossman et al. 2010), proximity to urban centers (James 2014), race and region combinations (Singh and Siahpush 2014; James and Cossman 2017; Cossman, James, and Wolf 2017), and race, region, population density, and homicide combinations (Murray et al. 2005, 2006). No matter how scientists differ in their various definitions, one thing remains clear: place matters.

A critical factor in understanding 'place' is knowing that it is dynamic. Recent decades have seen changes in macro-level restructuring of place. Places that were once rural are now suburban, economic opportunities have come and gone, and population shifts have changed the age, race, and ethnic makeup of communities (Lichter and Brown 2011). More closely related to health and mortality outcomes are factors such as having a regular source of medical care (Litaker et al. 2005), lifestyle and behaviors (Pampel and Rogers 2004; Cockerham 2005), physician and hospital shortages (Ricketts 1999; Li et al. 2009), and income inequality (Lowry 2004). These factors differ dramatically from one place to another and change over time. Despite this constant change, health outcomes persist in communities, generation after generation, suggesting that perhaps place is more important than population (Cossman et al. 2007).

Our work takes a new perspective on place-based mortality disparities, expanding upon prior research on the rural mortality penalty (Cossman et al. 2007; Cosby et al. 2008; Cossman et al. 2010; James 2014), by examining disparities in mortality persistence across combinations of rural region-division classifications. Persistence is important because it implies something greater than an observation at one cross section of time; additionally, it sheds light on the classic question in morbidity and mortality studies of whether the determination of an outcome is more associated with population or place. To be concise, we know that mortality is higher in rural than urban places and in southern than nonsouthern places. But what about combinations and subgroups of these previously broadly defined categories? We seek to answer one overarching question: What place has it the worst and how bad is it? We answer this question by measuring disparities across place in mortality persistence using a time series of 48 years of mortality data. 


\section{Data and methods}

We use the National Center for Health Statistics Compressed Mortality File from 1968 to 2015 (US DHHS), which measures all deaths by cause, age, race, sex, and county of residence at time of death for each year. Using five-year all-cause age-adjusted (2000 standard million) mortality rates (per 100,000) results in more stable rates for particular rural areas and provides rates that can be compared across counties $(\mathrm{N}=3,061$, no AK and $\mathrm{HI}$ ) and time. Population data is based on US Census estimates of total US, state, and county resident populations.

The focus of this research is on the temporal nature of geographic mortality patterns; thus, we analyze persistence of mortality. Persistence is measured over time using average mortality rates from ten time periods: 1968-1972, 1973-1977, 19781982, 1983-1987, 1988-1992, 1993-1997, 1998-2002, 2003-2007, 2008-2012, and 2013-2015. In each time period counties are designated as high, average, or low mortality based on the following: high mortality = greater than 1 standard deviation above the national mean, average mortality $=$ within 1 standard deviation of the national mean, and low mortality $=$ greater than 1 standard deviation below the national mean . For a county to be designated as persistently high mortality, it must be counted as high mortality in at least five out of ten time periods, not offset by low mortality counts i.e., over the period of 48 years, that county had an excessively high mortality rate at least half the time.

The primary categories of distinction in this research are census designations and rural-urban classifications. Census regions are Northeast, Midwest, South, and West, and divisions are New England, Middle Atlantic, East North Central, West North Central, South Atlantic, East South Central, West South Central, Mountain, and Pacific. ${ }^{3}$ Our analysis examines persistence of mortality across each of the four regions, and also refines this analysis to the census division level.

The Rural Urban Continuum Codes (RUCCs) represent the rural-urban distinctions in our work. This measurement is frequently used in research that explores place (Singh and Siahpush 2002; Hall, Kaufman, and Ricketts 2006; Cossman et al. 2010; James 2014). RUCCs are a nine-category classification of counties that are available through the US Department of Agriculture, Economic Research Service

\footnotetext{
${ }^{3}$ Census divisions are groups of states divided into subregions within each region. The Northeast has two divisions: Division 1 (New England) includes CT, ME, MA, NH, RI, VT; and Division 2 (Middle Atlantic) includes NJ, NY, PA. The Midwest has two divisions: Division 3 (East North Central) includes IN, IL, MI, $\mathrm{OH}, \mathrm{WI}$; and Division 4 (West North Central) includes IA, KS, MN, MO, NE, ND, SD. The South has three divisions: Division 5 (South Atlantic) includes DE, D.C., FL, GA, MD, NC, SC, VA, WV; Division 6 (East South Central) includes AL, KY, MS, TN; and Division 7 (West South Central) includes AR, LA, OK, TX. The West has two divisions: Division 8 (Mountain) includes AZ, CO, ID, NM, MT, UT, NV, WY; and Division 9 (Pacific) includes AK, CA, HI, OR, WA.
} 
(Cromartie and Parker 2017). Categories 0-3 are urban, with a population range from less than 250,000 to more than 1 million, representing roughly $83 \%$ of the American population. Categories 4-9 represent rural classifications based on population size and adjacency to an urban area, representing approximately $17 \%$ of the American population. Rural classifications 4 (adjacent to metro area) and 5 (not adjacent) are a population of 20,000 or more. RUCCs 6 (adjacent) and 7 (not adjacent) are a population of 2,500 to 19,999, and RUCCs 8 (adjacent) and 9 (not adjacent) are a population of less than 2,500. After 1996, code 0 merged into code 1 . Categories 6-9 most accurately represent rural, rather than suburban, and are thus utilized in this manuscript.

In our analysis, the three main sources of data are merged together to form a dataset of mortality rates for each year between 1968 and 2015, Census region and division codes, and RUCC indicators. This dataset allows for three sets of mortality rate comparisons: (1) rural vs. urban, (2) census region and division comparisons, and (3) rural-urban differences in mortality within each census region and division. Analyses answer the following questions: (1) Are persistently high mortality counties evenly distributed across rural and urban places? (2) Are persistently high mortality counties evenly distributed across census regions and divisions? (3) Are persistently high mortality counties disproportionately located in the South?

\section{Results}

\subsection{Preliminary findings}

The first analysis seeks to find if persistently unhealthy counties distribute evenly across rural and urban places. Unsurprisingly, they do not. There are 417 persistently high mortality counties, 313 (75\%) of which are rural, as shown in Table 1. Of all rural counties in the United States, $16 \%$ of them are persistently unhealthy compared to only $9 \%$ of urban counties. By census region the persistence of high mortality is most heavily concentrated in the South, with 367 of the 417 counties (88\%). The persistently unhealthy counties in the southern region are mostly concentrated in the South Atlantic (SA) and East South Central (ESC) divisions. In fact, $28 \%(\mathrm{~N}=153)$ of SA counties are classified as persistently high mortality, and $41 \%(\mathrm{~N}=148)$ of ESC counties fall into this designation. Although not reaching the level of its southern peers, the West South Central (WSC) has 66 counties - 14\% - that are persistently high mortality. No other census division has any more than 21 persistently high mortality counties, comprising no more than $3 \%$ of their regions' counties. Compared to Figure 1 in Cossman et al. (2007), the diffusion of persistently high mortality counties has actually expanded outside of the ESC division. That is, a decade ago the concentration in the ESC was 
even greater than today. A visual representation of the regional-divisional distribution of persistently high mortality counties is seen below in Figure 1.

Figure 1: Persistence of high mortality counties, 1968-2015, by census division

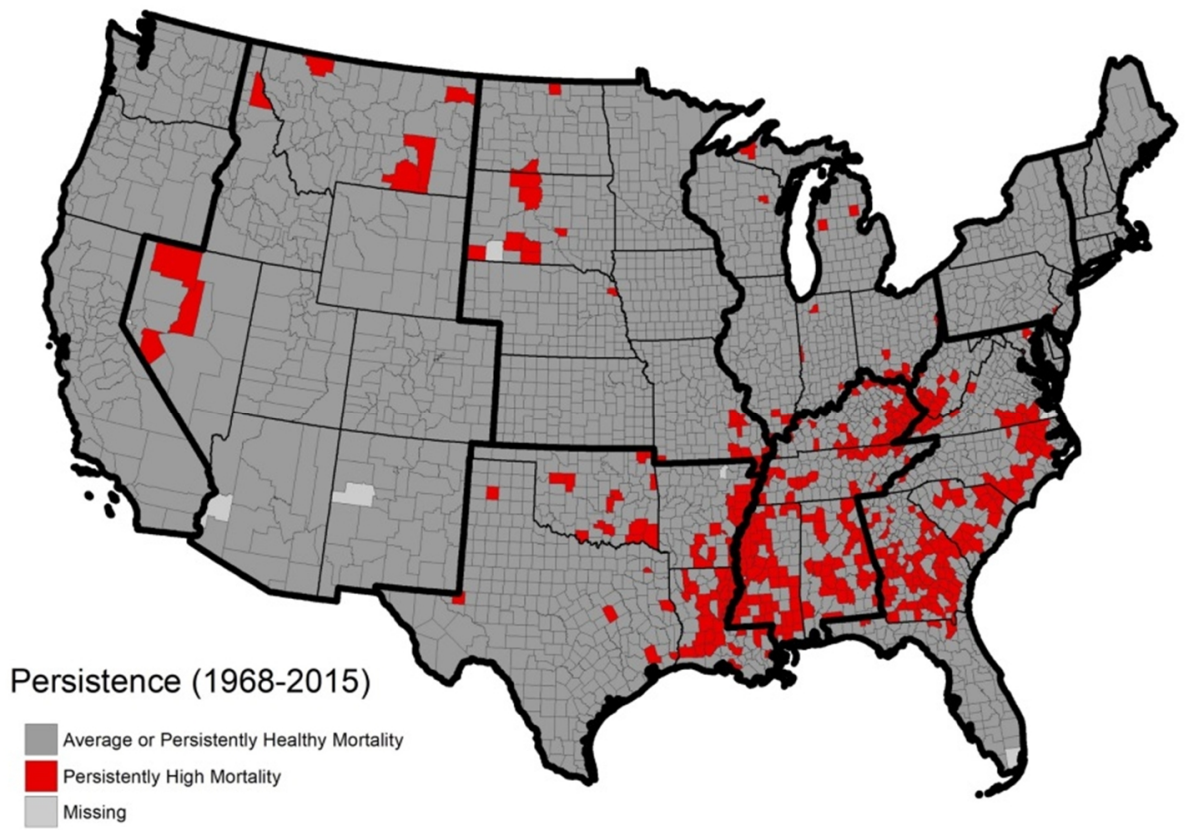

We next explored if the persistently unhealthy counties in the South are most heavily concentrated in the rural parts of the region-division. In the SA division, 71\% of persistently unhealthy counties are rural compared to $76 \%$ in the ESC division and $75 \%$ in the WSC division, as seen in Table 1 below. 
Table 1: Persistently unhealthy counties by rural-urban, region, and division

\begin{tabular}{lccc}
\hline Geography & \# Counties total & \# Counties unhealthy & \% of total \\
\hline Total US & 3061 & 417 & $13.6 \%$ \\
RUCC & & & \\
Urban & 1126 & 104 & $9.2 \%$ \\
Rural & 1935 & 313 & $16.2 \%$ \\
Census region & & & \\
Northeast & 217 & 2 & $0.9 \%$ \\
Midwest & 1053 & 40 & $3.8 \%$ \\
South & 1381 & 367 & $26.6 \%$ \\
West & 410 & 8 & $2.0 \%$ \\
Census division & & & \\
New England & 67 & 2 & $0.0 \%$ \\
Middle Atlantic & 150 & 19 & $1.3 \%$ \\
ENC & 437 & 21 & $4.3 \%$ \\
WNC & 616 & 153 & $3.4 \%$ \\
South Atlantic & 548 & 148 & $27.9 \%$ \\
ESC & 364 & 66 & $40.7 \%$ \\
WSC & 469 & 8 & $14.1 \%$ \\
Mountain & 277 & 0 & $2.9 \%$ \\
Pacific & 133 & & $0.0 \%$ \\
\hline
\end{tabular}

\subsection{Time series findings}

The previously established rural mortality penalty is shown in Figure 2 alongside mortality trends over time for the four census regions. Regional trend lines illustrate that three of the four regions - Northeast, Midwest, West - have mortality rates lower than urban and rural rates, but one region - the South - has a consistent pattern of higher mortality. The southern mortality rate has outpaced that of any other rural-urban or census region classification throughout the duration of our data, i.e., nearly five decades. The divergence between the southern rate and the urban reference category increases in each time period. While the disparity was only about 50 deaths per 100,000 in the late 1960s, it has increased to an alarming 100 deaths per 100,000 in the mid2010s. The findings shown in Figure 2 highlight the point that the previous literature's focus on rural-urban categories may be limited, and that the stark mortality differences may be more attributable to geographic region, or ultimately, division. 
Figure 2: Rural-urban vs. census region mortality trends, 1968-2015

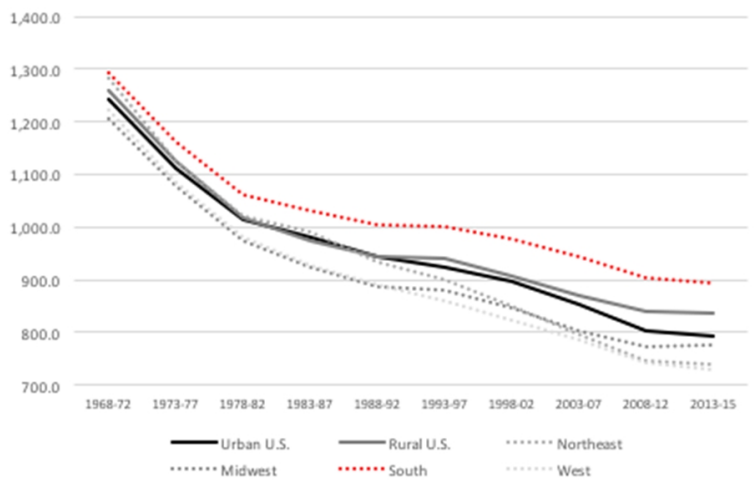

The excessively high rate of mortality in the South prompted further investigation into its three census divisions; SA, ESC, and WSC. The rural counties of the southern divisions are depicted in red in Figure 3, where all divisions experience higher mortality than the urban (and rural) reference category. Of the three southern census divisions, the rural counties of the ESC division exhibit the worst mortality outcomes, a rate in excess of 1,000 deaths per 100,000 . This finding is particularly alarming compared to the urban West North Central (WNC) where a rate of 740 is observed. Figure 3 illustrates a remarkable difference between the South and Midwest. This trend, while diverging in recent years, has existed since the late 1960s, supporting the hypothesis that the unhealthiest places are deeply persistent.

Figure 3: Rural-urban and South vs. Midwest mortality trends, 1968-2015

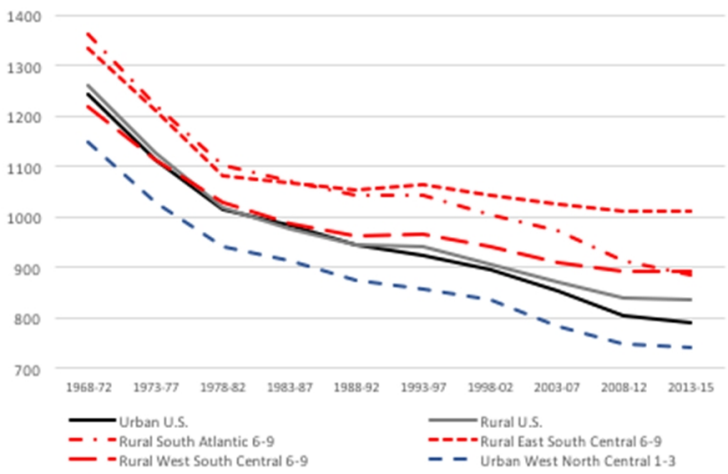


An examination of excess deaths between regions and divisions reveals an increasingly poor situation for rural ESC, as shown in Figure 4. At the beginning of the time series, the rural ESC experienced 100 excess deaths compared to urban America, and 200 excess deaths compared to urban WNC. In the most recent year it experiences 220 and 270 excess deaths, respectively. While the rural ESC has always been at a mortality disadvantage, it has been exacerbated in recent years. Figure 4 reveals another issue: While excess deaths have converged in rural SA and WSC, rural ESC continues to separate from the other rural South divisions.

\section{Figure 4: $\quad$ Excess deaths between urban United States and rural South divisions, 1968-2015}

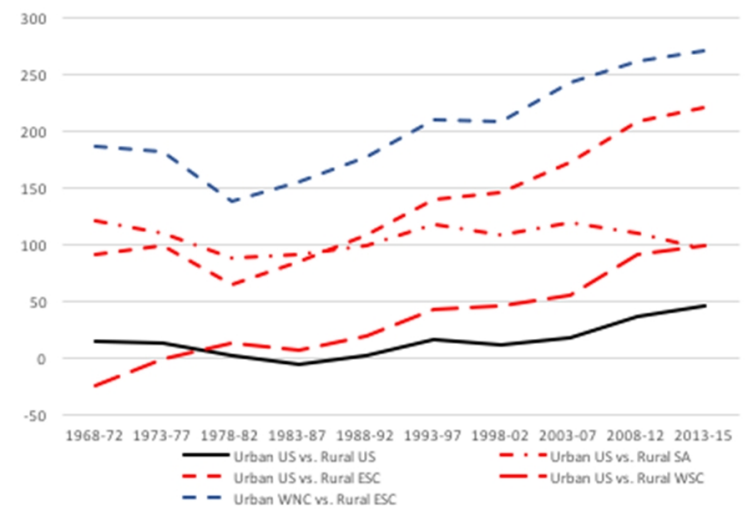

Lastly, one of the key factors driving regional differences in persistent mortality is the average annual rate of improvement. For decades, urban America has improved its mortality faster than other parts of the country, decreasing its collective mortality rate by 5\% annually. Rural America registers a slightly slower rate of improvement of $4.5 \%$. However, when examining rural divisions, it is evident that the rural US mortality penalty is fueled by conditions in the South. In particular, the rural WSC and rural ESC divisions lag considerably behind in mortality improvement, at $3.3 \%$ and $2.9 \%$ respectively. 
Figure 5: Average rate of improvement in mortality, 1968-2015

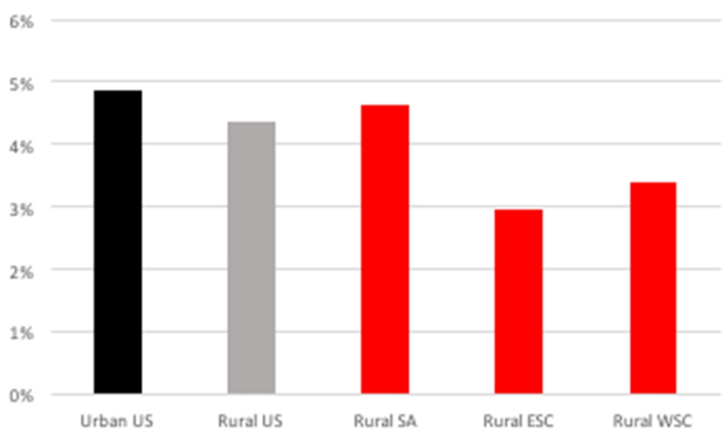

\section{Discussion}

This research moves forward the literature on place-based mortality disparities in two areas: (1) testing for persistence of poor health in place, and (2) identifying geographic disparities based on classifications that are not previously tested. A decade ago, Cosby et al. (2008) introduced the rural mortality penalty and how it has persisted over time. In more recent years, James (2014) documented marked disparities, not only between rural and urban places, but also between rural and rural places. Our findings add yet another layer of complexity, that of intra-rural differences across regions and divisions. We provide further confirmation that all rural places are not alike; in fact, they vary tremendously, not only by the region of the country in which they are located, but also by their smaller division. As hypothesized, we confirm that persistently high mortality counties are not evenly distributed across rural and urban places. They are not evenly distributed across regions and divisions, and they are disproportionately located in the rural South. (The persistently healthy places are located in the upper Midwest.)

To the first point, our work takes a temporal perspective on mortality patterns rather than one rooted at one cross section of time. This approach gets to the heart of the central point of persistence. Many counties around the nation are in a constant state of flux, but this group of unhealthy, rural, southern counties remains so despite any potential social, economic, or demographic shifts that may be occurring in and around them. Additionally, persistence also suggests that mortality patterns are generational. People are born, live, and die every day in these counties. Every year of mortality data includes new people, new cases. Yet even though the people change, the outcomes do not. This is comparable to Durkheim's idea of social facts, introduced more than 120 years ago, in that people are socialized to do the things they do, and thereby that 
socialization process exerts a powerful influence over the individuals (Durkheim, Lukes, and Halls 1982).

Prior work on the rural mortality penalty identified a rural-urban gap just shy of 100 deaths per 100,000 (Cosby et al. 2008). Using that number as a baseline comparison, the disparity outlined in the current work is a staggering 220 deaths per 100,000 in the ESC division, i.e., Kentucky, Tennessee, Mississippi, and Alabama. Further, it is nearly 300 deaths per 100,000 higher than the urban places in Missouri, Kansas, Iowa, Minnesota, and North Dakota, representing a staggering difference between America's Heartland and Dixieland.

The issue of unhealthy places is uniquely relevant at this moment in time, as life expectancy in the United States has decreased for the second year in a row, a statistical outlier not observed in more than 50 years (Fox 2017). The suspected drivers of this newly emerged trend? One, an increase in drug-opioid use. Two, smoking behaviors are more attributable to mortality in the South Central states than in other divisions (Fenelon 2013). Three, the historical concentration of poverty in the rural south has been associated with mortality for decades (Fenelon 2013). Considering that the ESC division contains roughly 19 million people, an estimated 6,600 excess deaths occur annually. Projecting that out over decades results in hundreds of thousands of deaths that would have been delayed given a death rate similar to other geographic regions. The slow rate of improvement in the rural ESC counties is one of the main drivers of the persistent mortality disadvantage. Unfortunately, many in the rural South are falling behind in the race for longevity and good health. We conclude by answering the original question; what place has it the worst and how bad is it? The rural parts of the South Central states have it the worst, by a landslide. 


\section{References}

Cockerham, W.C. (2005). Health lifestyle theory and the convergence of agency and structure. Journal of Health and Social Behavior 46(1): 51-67. doi:10.1177/002214650504600105.

Cosby, A., Neaves, T., Cossman, R., Cossman, J., James, W., Feierabend, N., Mirvis, D., Jones, C., and Farrigan, T. (2008). Preliminary evidence for an emerging non-metropolitan mortality penalty in the United States. American Journal of Public Health 98(8): 1470-1472. doi:10.2105/AJPH.2007.123778.

Cossman, J., Cossman, R., James, W., Campbell, C., Blanchard, T., and Cosby, A. (2007). Persistent clusters of mortality in the United States. American Journal of Public Health 97(12): 2148-2150. doi:10.2105/AJPH.2006.093112.

Cossman, J., James, W., Cosby, A., and Cossman, R. (2010). Underlying causes of the emerging nonmetropolitan mortality penalty. American Journal of Public Health 100(8): 1417-1419. doi:10.2105/AJPH.2009.174185.

Cossman, J., James, W., and Wolf, J. (2017). The differential effects of rural health care access on race-specific mortality. Social Science and Medicine - Public Health 3: 618-623.

Cromartie, J. and Parker, T. (2017). Rural classifications [electronic resource]. Washington, D.C.: Economic Research Service, US Department of Agriculture. http://www.ers.usda.gov/topics/rural-economy-population/rural-classifications/ what-is-rural.aspx\#.UtWLlPvAbng.

Durkheim, E., Lukes, S., and Halls, W.D. (1982). The rules of the sociological method. The Free Press: New York. doi:10.1007/978-1-349-16939-9.

Fenelon, A. (2013). Geographic divergence in mortality in the United States. Population Development Review 39(4): 611-634. doi:10.1111/j.1728-4457. 2013.00630.x.

Fox, M. (2017, December 21). U.S. life expectancy falls for second straight year: As drug overdoses soar. NBC News. https://www.nbcnews.com/storyline/americasheroin-epidemic/u-s-life-expectancy-falls-second-straight-year-drug-overdosesn831676.

Hall, S.A., Kaufman, J.S., and Ricketts, T.C. (2006). Defining urban and rural areas in US epidemiologic studies. Journal of Urban Health 83(2): 162-175. doi:10.1007/s11524-005-9016-3. 
James, W. (2014). All rural places are not created equal: Revisiting the rural mortality penalty in the United States. American Journal of Public Health 104(11): 21222129. doi:10.2105/AJPH.2014.301989.

James, W. and Cossman, J. (2017). Long-term trends in black and white mortality in the rural United States: Evidence of a race-specific rural mortality penalty. The Journal of Rural Health 33(1): 21-31. doi:10.1111/jrh.12181.

Lichter, D.T. and Brown, D.L. (2011). Rural America in an urban society: Changing spatial and social boundaries. Annual Review of Sociology 37: 565-592. doi:10.1146/annurev-soc-081309-150208.

Li, P., Schneider, J.E., and Ward, M.M. (2009). Converting to critical access status: How does it affect rural hospitals' financial performances? Inquiry 46(1): 46-57. doi:10.5034/inquiryjrnl_46.01.46.

Litaker, D., Koroukian, S.M., and Love, T.E. (2005). Context and healthcare access. Medical Care 43(6): 531-540. doi:10.1097/01.mlr.0000163642.88413.58.

Lowry, A. (2014, March 15). Income gap, meet the longevity gap. New York Times. http://www.nytimes.com/2014/03/16/business/income-gap-meet-the-longevitygap.html?_r=0.

Murray, C.J.L., Kulkarni, S., and Ezzati, M. (2005). Eight Americas: New perspectives on US health disparities. American Journal of Preventive Medicine 29(5): 4-10. doi:10.1016/j.amepre.2005.07.031.

Murray, C., Kulkarni, S., Michaud, C., Tomijima, N., Bulzacchelli, M.T., Iandiorio, T.J., and Ezzati, M. (2006). Eight Americas: Investigating mortality disparities across races, counties, and race-counties in the United States. PLoS Medicine 3(12): 1513-1524. doi:10.1371/journal.pmed.0030545.

Pampel, F.C. and Rogers, R.G. (2004). Socioeconomic status, smoking, and health: A test of competing theories of cumulative advantage. Journal of Health and Social Behavior 45(3): 306-321. doi:10.1177/002214650404500305.

Ricketts, T.C. (1999). Rural health in the United States. New York: Oxford University Press.

Singh, G.K. and Siahpush, M. (2002). Increasing rural-urban gradients in US suicide mortality, 1970-1997. American Journal of Public Health 92(7): 1161-1167. doi:10.2105/AJPH.92.7.1161. 
Singh, G.K. and Siahpush, M. (2014). Widening rural-urban disparities in life expectancy, U.S., 1969-2009. American Journal of Preventive Medicine 46(2): e19-e29. doi:10.1016/j.amepre.2013.10.017.

United States Department of Health and Human Services (US DHHS), Centers for Disease Control and Prevention (CDC), and National Center for Health Statistics (NCHS). Compressed Mortality File (CMF) on CDC WONDER online database [electronic resource]. Washington, D.C., Atlanta, Hyattsville: DHHS, CDC, NCHS. https://wonder.cdc.gov/mortSQL.html. 
James, Cossman \& Wolf: Persistence of death in the United States 